\title{
Influence of Two Self-Etching Primer Systems on Enamel Adhesion
}

\author{
Márcio Antônio Paraizo BORGES ${ }^{1}$ \\ Irma Cunha MATOS ${ }^{1}$ \\ Kátia Regina Hostílio Cervantes DIAS ${ }^{2}$ \\ ${ }^{1}$ Brazilian Navy, Navy Central Clinic, Rio de Janeiro, RJ, Brazil \\ ${ }^{2}$ Department of Restorative Dentistry, School of Dentistry, State University of Rio de Janeiro, Rio de Janeiro, RJ, Brazil
}

\begin{abstract}
The aim of this study was to compare two self-etching and a total-etch adhesive systems by assessing their shear bond strength to bovine enamel and the microleakage on class $\mathrm{V}$ composite restorations prepared on bovine enamel. Bovine teeth selected and allocated in three groups: Group 1: Scothbond Multi-Purpose; Group 2: Clearfil Liner Bond 2V; Group 3: Etch \& Prime 3.0. For the microleakage test, each group was composed of ten class $\mathrm{V}$ restorations on the buccal surface. Two examiners attributed scores ranging from 0 (without leakage) to 3 (maximum leakage) to determine silver nitrate penetration at enamel-composite interface. Microleakage data were analyzed statistically by Kruskal-Wallis and Mann-Whitney tests at 5\% significance level. For the bond strength test, ten teeth of each group were included, had their buccal surfaces flattened in order to obtain a 3-mm-diameter area to which a resin cylinder was bonded. After one week, the specimens were tested in shear strength at a crosshead speed of $0.5 \mathrm{~mm} / \mathrm{min}$. Bond strength data were treated by ANOVA and LSD tests at 5\% significance level. The debonded interfaces were examined under scanning electron microscopy. No leakage was observed along enamel margins. Means $( \pm$ SD) in MPa were: $18.75( \pm 5.83), 22.17( \pm 4.95)$ and 14.93 ( \pm 6.7$)$ for Groups 1, 2 , and 3, respectively. According to the results of this study, the self-etching primer systems presented statistically similar behavior $(\mathrm{p}>0.05)$ to that of the total-etch adhesive system (used as a control), not only regarding marginal leakage at bovine enamel-composite resin interface, but also regarding the shear bond strength of the bovine enamel. However, the self-etching primer systems differed significantly $(\mathrm{p}>0.05)$ to each other, with better results for Clearfil Liner Bond $2 \mathrm{~V}$. In conclusion, the self-etching primer systems had a performance comparable to that of the total-etch adhesive system.
\end{abstract}

Key Words: self-etching primer, bond strength, enamel adhesion, microleakage.

\section{INTRODUCTION}

In 1952, Kramer and McLean (1) published an article reporting their first experimental study on adhesion, in which altered impregnation of dentin surface, resulting from the interaction with glyrecophosphate dimethacrylate (GPDM) was observed. Few years later, after observing the industrial use of phosphoric acid, which increases the adhesion of paints to the metal surface, Buonocore (2) introduced the acid-etching technique to dentistry with the goal of increasing the actual retention of acrylic resins to tooth enamel. Acidetching became one of the keystones of modern dentistry, allowing the preparation of more conservative cavities, reduction of microleakage at tooth-restoration inter- face, prevention of recurrent caries and marginal discoloration, and reduction of postoperative sensibility (3).

Acid etching dissolves enamel crystals in the prism structure, which results in a roughened surface that will allow monomer diffusion, producing micromechanical interlocking within this etched structure (4). This procedure creates a porous enamel surface layer that ranges in depth from 5 to $50 \mu \mathrm{m}$ (5). Shear bond strengths generally range from 20 to $25 \mathrm{MPa}$ when resin-based composites are bonded to enamel etched with $37 \%$ phosphoric acid (6).

Conventional dentin bonding systems require the sequencial application of conditioner, dentin primer and bondin agent in several clinical steps (6). Recent studies have demonstrated that the conditioners used in 
conventional adhesive systems, result in an excessive depth of etched dentin. Therefore, primers and the adhesive resin cannot penetrate satisfactorily the etched surface, leaving unfilled microscopic voids, even if marginal gaps are not present. This phenomenon, known as nanoleakage, was first described by Sano et al., in the 1990's (7).

To prevent the collapse of demineralized dentin surface and simplify the technical application, Watanabe (8) devised an adhesive system containing acidic monomers, which dissolve the smear layer, incorporating it into the demineralized dentin, and encapsulating the collagen fibers and hydroxyapatite crystals.

Self-etching bonding systems contain primers, like 2-hydroxyethyl methacrylate (HEMA) or diphentaerythritol penta-acrylateomonophosphate (PENTA), in the same bottle that encolses a low viscosity resin. A solvent (ethanol or acetone) is added to work on water removal to facilitate the exchange of water for monomers inside the collagen lattice, producing the hybrid layer (9). Although this results in an appropriate adhesion to the dentinal structure, with a smaller number of clinical steps, there is still some concern regarding bonding resistance to enamel, which might disregard enamel bond strength in order to simplify clinical application (4).

Therefore, the aim of this study was to compare two self-etching and a total-etch adhesive systems by assessing their shear bond strength to bovine enamel and the microleakage on class $\mathrm{V}$ composite restorations prepared on bovine enamel.

\section{MATERIAL AND METHODS}

The tested materials were: Scotchbond MultiPurpose total-etch adhesive system (3M/ESPE, St Paul, MN, USA), Clearfil Liner Bond 2V self-etching adhesive system (Kuraray, Osaka, Japan) and Etch \& Prime 3.0 self-etching adhesive system (Degussa AG, Geschaftsbereich Dental, Hanau, Germany).

\section{Microleakage Test}

Thirty recently extracted bovine permanent mandibular incisors with no cracks, hypoplastic areas or visible caries, which had been stored in distilled water at room temperature for up to 12 weeks, had their buccal surfaces prepared with class V cylindrical cavities, with occlusal and cervical margins in enamel. The length of the active part of a \#330 tungsten-carbide bur $(2 \mathrm{~mm})$ limited the depth of the cavities. The occlusogingival and mesiodistal dimensions were $3 \mathrm{~mm}$. The cavosurface angle was beveled as close as possible to $45^{\circ}$, with the same bur. The specimens were randomly assigned to 3 groups of ten teeth each and treated with the adhesive systems, according to the manufacturer's instructions. Thereafter, a light-cured composite resin (TPH Spectrum, Dentsply/Caulk Milford, DE, USA) was inserted in three increments, each increment being light-cured for $40 \mathrm{~s}$. A curing unit (Heliomat, Vigodent S. A. Indústria e Comércio, Rio de Janeiro, RJ, Brazil) was connected to a variable transformer in order to adjust the light intensity to $400 \mathrm{~mW} / \mathrm{cm}^{2}$, measurements being performed with a curing radiometer (Demetron Research Corp., Danbury, CT, USA). After the curing cycle, all specimens were stored in distilled water at room temperature for 7 days and then polished with tips and disks for composite finishing.

The dental surfaces were dried and covered with two nail polish layers, leaving an uncovered area of 2 $\mathrm{mm}$ exposed around the restoration. Complementary sealing with Cavit-W (3M/ESPE) was done on the apexes to prevent penetration of the tracer agent in all the areas of the tooth, as fissures or structural defects that had not been observed during selection of the teeth. Thus, dye penetration would be restricted to the cavity margins. The specimens were immersed in an aqueous solution of $50 \%$ silver nitrate for $24 \mathrm{~h}$. Next, the teeth were washed and dipped in a ray-X developing solution for 2 hours. Thereafter, they were removed from the solution and washed in running water, so that trace agent excess could be removed. The nail polish layer was entirely removed with gauze soaked in acetone, and then, teeth were washed again in running water, dried and embedded in polyurethane resin using a previously prepared silicone mould.

Twenty-four hours after inclusion, the teeth were removed from the moulds and bisected longitudinally following the buccolingual groove direction with a water-cooled double-faced diamond disk (Superflex 273D, Horico, Berlin, Germany) at lowspeed, thus obtaining two halves per tooth. The halves were flattened and polished with a 600 -grit abrasive paper. Double-blinded microleakage analysis was carried out by two skilled examiners under light stereomicroscopy at X 40 magnification. The following 
score system was used: $0=$ without leakage; $1=$ cervical or occlusal leakage, not reaching the axial wall; $2=$ cervical or occlusal leakage reaching the axial wall; and, $3=$ Leakage past the axial or cervical wall, towards the pulp. Microleakage data were analyzed statistically by Kruskal-Wallis and Mann-Whitney tests at 5\% significance level.

\section{Bond Strength Test}

Thirty recently extracted bovine permanent incisors were collected and stored in distilled water at $37^{\circ} \mathrm{C}$. All roots were sectioned transversally with a water-cooled doublefaced diamond disk. The buccal surfaces were then placed on a glass plate with the most convex region faced downwards. A metal ring was placed around each specimen to act as a mould, filled with polyurethane resin and allowed to cure for about $24 \mathrm{~h}$, leaving the enamel buccal surface exposed. The teeth were embedded in a way that the buccal surface was kept parallel to the force during the shear test.

Each specimen was flattened and polished using 320400- and 600-grit silicon carbide paper until the enamel area was sufficiently exposed. The specimens were then removed from the metal rings and placed in distilled water.

The specimens were randomly allocated in 3 groups $(n=10)$. The adhesive systems were applied according to the manufacturer's instructions. Enamel surfaces were coated with TPH Spectrum (Dentsply/ Caulk), forming a cylinder with height of $6 \mathrm{~mm}$ and diameter of $3 \mathrm{~mm}$. The cylinders were built with three 2-mm-thick composite resin increments, each one lightcured for $40 \mathrm{~s}$. The output of the light-curing unit was measured after every specimen with a curing radiometer to ensure a minimum irradiance of $400 \mathrm{~mW} / \mathrm{cm}^{2}$. The polymerized specimens were stored in $100 \%$ relative humidity at room temperature for 7 days. The specimens were tested in shear mode in a universal testing machine (Emic Dl 500 MF, Emic, São José dos Pinhais, PR, Brazil) at a crosshead speed of $0.5 \mathrm{~mm} / \mathrm{min}$. Shear bond strength in MPa was calculated from the peak load at failure, divided by the specimen surface area. Bond strength data were treated by ANOVA and LSD tests at $5 \%$ significance level.

After shear test, the resin sides of fractured specimens were mounted on aluminum stubs, sputtercoated with gold and observed by scanning electron microscopy (SEM) at 200x magnification to assess the failure modes.

\section{RESULTS}

\section{Microleakage Test}

The three adhesive systems were able to prevent silver nitrate leakage at the resin-enamel interface. There was no statistically significant difference among the groups $(\mathrm{p}>0.05)$.

\section{Bond Strength Test}

Shear bond strength means in $\mathrm{MPa}( \pm \mathrm{SD})$ of the studied groups were as follows: G1: $18.75 \pm 5.83, \mathrm{G} 2$ : $22.17 \pm 4.95$ and G3: $14.93 \pm 6.79$. ANOVA detected a significant difference $(\mathrm{p}<0.05)$ between the groups. LSD test showed significant difference $(\mathrm{p}<0.05)$ only between Groups 2 and 3. The self-etching primer adhesive systems presented similar behavior to that of the control group $(p>0.05)$. However, statistically significant difference $(\mathrm{p}<0.05)$ was found between them, Clearfil Liner Bond $2 \mathrm{v}$ presenting better results than Etch \& Prime 3.0.

\section{SEM Analysis}

The failure modes (\%) after debonding were as follows G1: $40 \%$ adhesive failures, $60 \%$ cohesive failures; G2: $25 \%$ adhesive failures, $75 \%$ cohesive failures; G3: $60 \%$ adhesive failures, $40 \%$ cohesive failures.

Group 1 showed a high frequency of mixed failure. Resin tag penetration was regular and prolonged, suggesting an appropriate penetration of the bonding agent into the phosphoric acid-etched enamel surface (Fig. 1).

In Group 2, the failure mode was predominately cohesive in enamel. A quite regular and prolonged penetration of Clearfil LinerBond $2 \mathrm{v}$ adhesive into the enamel surface was observed, characterizing a great diffusion of the acidic primer through the substrate (Fig. 2).

Microscopic enamel fracturing at the adhesive interface is shown on Figure 3 (Group 3), however with a smaller frequency when compared to the other groups. Minimal resin penetration was observed, with shorter and irregular resin tags, presenting a smaller infiltration and diffusion of the Etch \& Prime 3.0 system into the bovine enamel. 


\section{DISCUSSION}

Microleakage and bond strength tests are recognized as reliable means to assess the adhesive resistance and to demonstrate if leakage at the resin-enamel inter-

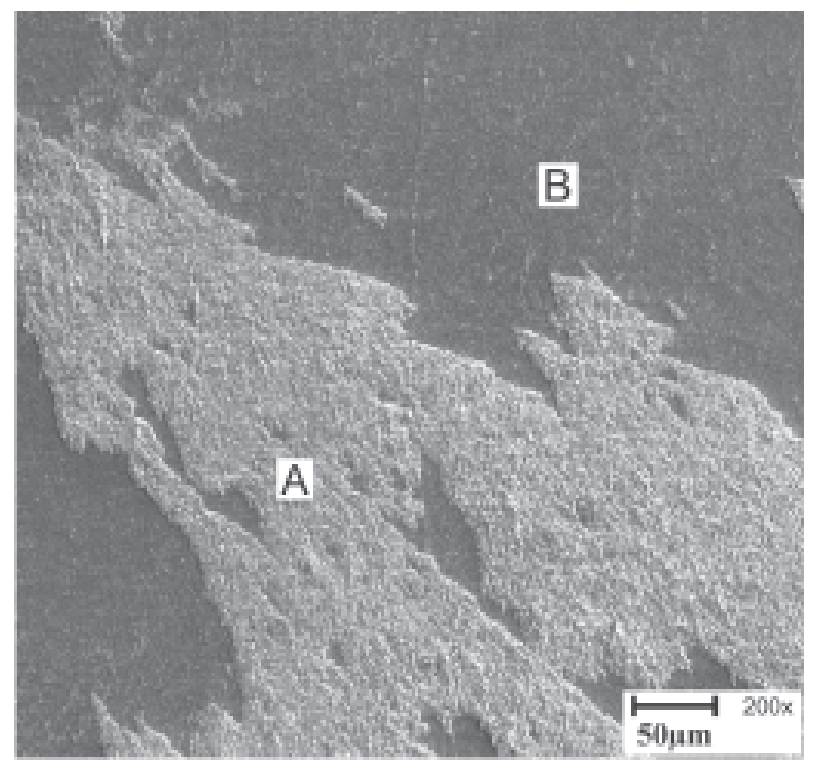

Figure 1. Photomicrograph of a debonded resin surface (Group 1). Mixed failure. A: cohesive failure in enamel; B: adhesive failure.

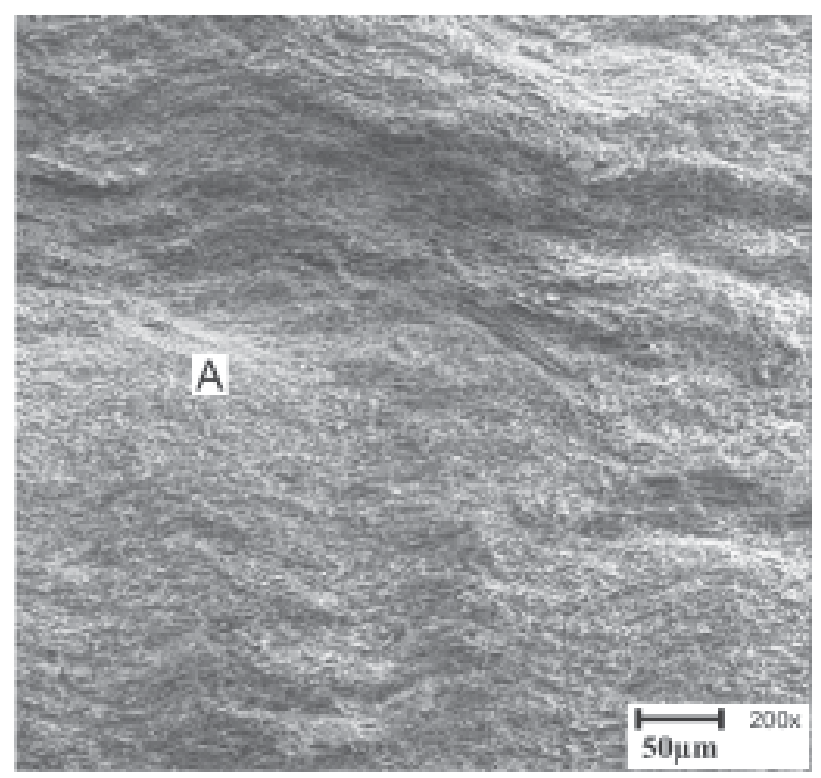

Figure 2. Photomicrograph of a debonded resin surface (Group 2). Cohesive failure in enamel (A). face can be avoided. These tests have been widely employed in dentistry. However, they require the use of a large number of teeth. Given that human teeth are getting more and more difficult to be obtained, bovine teeth have been used as a substitute for human teeth, as it has been suggested that the bovine teeth could simulate human teeth if the test surfaces are enamel or superficial dentin $(10,11)$.

In the present study, no silver nitrate penetration occurred along the enamel margins, which indicates that the three adhesive systems used were effective in preventing marginal leakage. These findings confirmed the effectiveness of the acid-etch technique associated with adhesive systems in microleakage prevention. Similar results have been found when Clearfil Liner Bond 2v and Etch \& Prime 3.0 were used (12).

Shear bond strength means recorded for Scothbond Multi-Purpose Plus (control group) was $18.75 \pm 5.83 \mathrm{MPa}$, which is consistent with the findings of previous studies using similar methodology $(11,13)$. These results are due to enamel inorganic structure pattern, which contributes to adhesive resin penetration into porosities created by phosphoric acid etching, thus providing considerably high shear bond strength (2).

The self-etching primer adhesive systems presented shear bond strength means similar to that of the control group ( $p>0.05): 22.17 \pm 4.95 \mathrm{MPa}$ for Clearfil

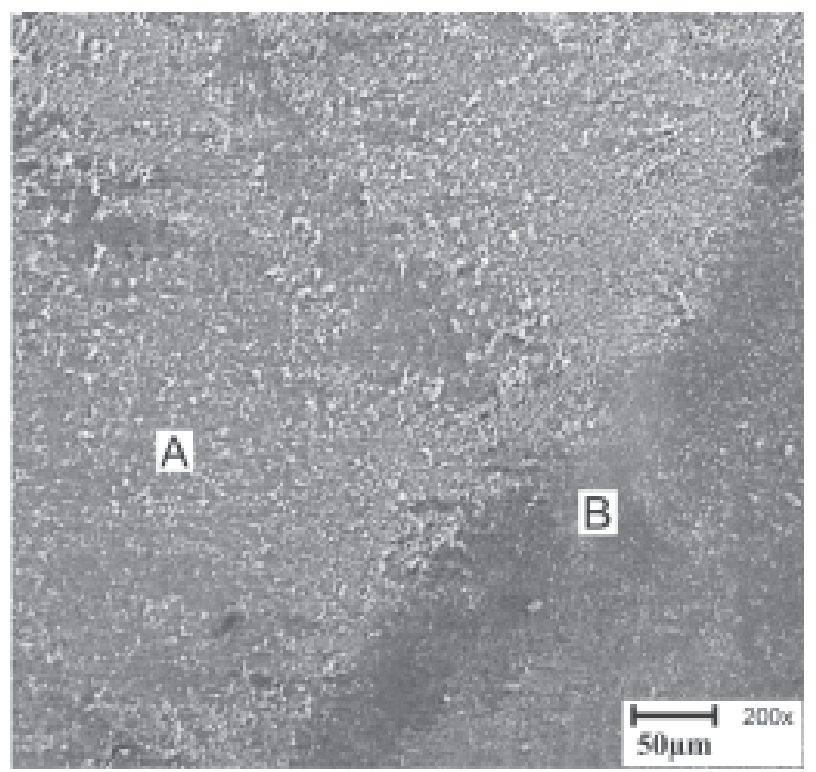

Figure 3. Photomicrograph of a debonded resin surface (Group 3). Mixed failure. A: cohesive failure in enamel; B: adhesive failure. 
Liner Bond 2V and $14.93 \pm 6.79 \mathrm{MPa}$ for Etch \& Prime 3.0. However, significant difference $(p<0.05)$ was found between the self-etching primer systems, Clearfil Liner Bond $2 \mathrm{~V}$ presenting better results.

Clearfil Liner Bond $2 \mathrm{~V}$ contains an acidic monomer 10-MDP (10-methacrylodecamethylene phosphoric acid) that seems to be more effective in yielding a stronger shear bonding than other systems (14). Failure mode corroborated this result.

In this study, Etch \& Prime 3.0 showed lower shear bond strength means than Clearfil Liner Bond 2V. Several reasons have been advocated to account for the suboptimal performance of self-etching primers: 1) the combination of acidic hydrophilic and hydrophobic monomers into a single step may compromise polymerization of the adhesive, 2) the inherent weak strength of the adhesive polymer, and 3) the lower degree of polymerization of the resin monomer due to a major solvent/oxygen inhibition efect during light activation of these materials (15).

Several studies have been developed to assess the shear bond strength of self-etching primer adhesive systems (16) and have reported that these systems are capable of providing an acceptable shear bond. However, further research is required to demonstrate the effectiveness of the different commercial brands of self-etching primer systems currently available in the market, in order to increase their application in dentistry. It has been demonstrated that the shear bond strength of self-etching primers to the bovine enamel varies according to the chemical composition of the tested adhesive systems (17).

The analysis of the debonded interfaces showed that while there was a high incidence of cohesive failure in enamel in Groups 1 and 2 (Figs. 1 and 2), this did not occur with the Etch \& Prime 3.0 (Fig. 3), which presented a high incidence of adhesive failures and shorter resin tags. This suggests that a greater superficial impregnation of the adhesive in the substratum might be present.

Glasspoole et al. (16) studied the effect of several enamel surface treatments on bovine enamel surface and assessed the shear bond strength of a compomer to the bovine enamel. These authors found that the acid etching depth and resin penetration in the enamel surface are directly related to the shear bond strength of the material to the dental surface, which confirms the results obtained in the present study.
The degree of impregnation of the self-etching primers in enamel seems to be minimal, even if enamelresin bonding is acceptable (18). However, Barkmeier et al. (19) obtained deep etchings when enamel was demineralized and the resin replicas were examined. Although a superficial bond can produce a high initial shear bond, its resistance to thermal cycles or occlusal tension should be established by clinical studies.

Miyazaki et al. (20) reported that bonding durability using thermocycling in water between 5 and $60^{\circ} \mathrm{C}$ for more than 30,000 cycles simulating adhesion fatigue. In this study, the two adhesive systems that showed the highest fatigue effect in the shear bond strength to enamel were the self-etching primer systems (approximately $55 \%$ of its initial shear strength). The best results were provided by two total-etch adhesive systems, which did not suffer practically any influence from thermocycling, maintaining $96 \%$ of its initial shear bond strength. These results showed that self-etching primer adhesive systems might undergo fatigue and have their durability at risk. Clinical trials are required to determine whether these weak bonds between enamel and resin will support the occlusal tensions.

According to the results of this study, the selfetching primer systems presented similar behavior to that of the total-etch adhesive system, not only regarding marginal leakage at bovine enamel-composite resin interface, but also concerning the shear bond strength of the bovine enamel. However, the self-etching primer systems differed significantly to each other, with better results for Clearfil Liner Bond $2 \mathrm{~V}$.

Further studies on the influence of self-etching primers on enamel adhesion are required and may provide valuable information on adhesive systems to clinicians.

\section{RESUMO}

O objetivo deste estudo foi comparar um sistema adesivo que utiliza condicionamento ácido total com outros contendo primers autocondicionantes em sua composição, quando aplicados ao esmalte bovino. Para isto, foram realizados testes de microinfiltração com corante e testes de resistência de união ao cisalhamento. Os dentes bovinos foram divididos em três grupos, de acordo com o sistema adesivo empregado: Grupo 1 (controle) - Scotchbond Multi-Uso Plus (3M); Grupo 2- Clearfil Liner Bond 2V (Kuraray); e Grupo 3- Etch \& Prime 3.0 (Degussa). Para microinfiltração, cada grupo foi composto de dez restaurações classe V na superfície vestibular dos dentes e restauradas com o compósito TPH (Dentisply). A avaliação foi realizada por dois avaliadores previamente calibrados, usando um sistema de escore crescente de 0 (sem infiltração) até 3 (infiltração além da parede 
axial), dependendo do grau de penetração de um corante a base de nitrato de prata. Para o teste de resistência ao cisalhamento, 10 dentes de cada grupo foram incluídos em um tubo de metal, usando uma resina autopolimerizável. Suas superfícies vestibulares foram desgastadas até a obtenção de uma área de adesão com diâmetro de $3 \mathrm{~mm}$. Sobre estas superfícies foram construídos cilindros de resina composta TPH. Após uma semana, foram submetidos ao ensaio de cisalhamento, a uma velocidade de 0,5 $\mathrm{mm} / \mathrm{min}$. Após a ruptura, as superfícies dos cilindros de resina composta foram recolhidas para observação em microscópio eletrônico de varredura. Para os testes de microinfiltração, os resultados foram tratados estatisticamente por Kruskal-Wallis e Mann-Whitney ( $p>0,05)$. O teste de microinfiltração não revelou diferença entre os grupos. Os resultados do teste de cisalhamento foram tratados por ANOVA e teste $\operatorname{LSD}(\mathrm{p} \leq 0,05)$. As médias e desvios padrão em MPa foram: G1: 18,75 \pm 5,83; G2: 22,17 \pm 4,95; G3: 14,93 $\pm 6,7$. Não houve diferença estatisticamente significante entre o grupo controle e os autocondicionantes(p> $0,05)$, somente nos grupos dos autocondicionantes entre si ( $\mathrm{p}<$ $0,05)$ (LSD). A análise dos resultados permitiu concluir que os sistemas autocondicionantes tiveram comportamento semelhante aos sistemas adesivos que usam ácido fosfórico, quando aplicados em esmalte bovino.

\section{REFERENCES}

1. Van Meerbeek B, Perdigão J, Lambrechts P, Vanherle G. The clinical performance of adhesives. J Dent 1998;26:1-20.

2. Buonocore MG. A simple method of increasing the adhesion of acrylic filling materials to enamel surfaces. J Dent Res 1955;34:849-853.

3. Alani AH, Toh CG. Detection of microleakage around dental restorations: a review. Oper Dent 1997;22:173-185.

4. Miyasaki M, Hirohata N. Influence of self-etching primer drying team on enamel bond strength of resin composites. J Dent 1999;27:203-207.

5. Milia E, Lullai MR. In vivo effect of the self-etching primer on dentin. Am J Dent 1999;12:167-171.

6. Chiba, Y, Yamaguchi, K, Miyazaki, M, Tsubota, K, Takamizawa, T, Moore, B.K. Effect of air-drying time of single-application self-etch adhesives on dentin bond strength. Oper Dent 2006;31:233-239.

7. Cure H, Shono T, Sonoda H, Takatsu T, Ciucchi B, Oak R, Pashley DH. Relationship between surface area goes adhesion and tensile bond strength - evaluation of the personal com- puter-tensile bond test. Dent Mater 1994;10:236-240.

8. Watanable I, Nakabayashi N, Pashley DH. Bonding to ground dentin using the self-etching Phenyl-P primer. J Dent Res 1994;73:1212-1220.

9. Nakabayashi N, Kojima K, Masuhara E. The proportion of adhesion by the infiltration of monomers into tooth substrates. J Biomed Mater Res 1982;16:265-273.

10. Nakamichi I, Iwaku M, Fusayama T. Bovine teeth as possible substitutes in the adhesion test. J Dent Res 1983;62:10761081 .

11. Amano S, Yamamoto A, Tsubota K, Rikuta A, Miyazaki M, Platt JA, Moore BK. Effect of thermal cycling on enamel bond strength of single-step self-etch systems. Oper Dent 2006;31:616-622.

12. Hanning M, Reinhardt KJ, Bott B. Self-etching primer vs phosphoric acid: an alternative concept goes composite to enamel bonding. Oper Dent 1999;24:172-180.

13. Gordan VV, Vargas MA, Cobb DS, Denehy GE. Evaluation of adhesive systems using acidic primers. Am J Dent 1997; 10:219-223.

14. Konno ANK, Sinhoreti MAC, Consani S, Sobrinho LC, Consani RLX. Storage effect of the shear bond strength of adhesive systems. Braz Dent J 2003;14:42-47.

15. Toledano, M, Osorio, R, Albaladejo, A, Aguilera, FS, Tay, FR, Ferrari, M. Effect of cyclic loading on the microtensile bond strengths of total-etch and self-etch adhesives. Oper Dent 2006;31:25-32.

16. Chiba Y, Yamaguchi K, Miyazaki M, Tsubota K, Takamizawa $\mathrm{T}$, Moore BK. Effect of air-drying time of single-application self-etch adhesives on dentin bond strength. Oper Dent 2006;31-32, 233-239.

17. Lopes GC, Marson FC, Vieira, LC, Kettle AM, Baratieri LN. Composite bond strength to enamel with self-etching primers. Oper Dent 2004;29:424-429.

18. Watanable I, Nikaido T, Nakabayashi N. Effect of adhesion promoting monomers on adhesion to ground dentin. J Jpn Dent Mater 1990;9:888-893.

19. Barkmeier WW, Los SA, Triolo PT. Bond strengths and SEM evaluation of Clearfil Liner Bond 2. Am J Dent 1995;8:289293.

20. Miyazaki M, Sato M, Onose H. Durability of enamel bond strength of simplified bonding systems. Oper Dent $2000 ; 25: 75-80$.

Accepted May 8, 2007 